\title{
A New Process of Manufacturing “Oxygen-free” Gd
}

\author{
$\mathrm{Li} \mathrm{Li}^{1}, \quad$ Li Guoling ${ }^{1,4}, \quad \mathrm{Xu} \mathrm{Li}^{2}, \quad \mathrm{Xiong} \mathrm{Yifu}^{3}, \quad \mathrm{Li}^{\prime} \mathrm{Xingguo}^{1}$ \\ ${ }^{1}$ Peking University, Beijing 100871, China; ${ }^{2}$ Future Science \& Technology Park, State Grid Smart Grid Research Institute, Beijing 102211, \\ China; ${ }^{3}$ Institute of Materials, Mianyang 621907, China; ${ }^{4}$ Qingdao University, Qingdao 266071, China
}

\begin{abstract}
Oxygen-free" Gd was fabricated by hydrogen plasma arc melting (HPAM). The HPAM is more different than the traditional Ar plasma arc melting (PAM) in Oxygen removal. It is attributable to the hydrogen atoms dissociated and activated in high temperature HPAM. In addition an increased diffusion of oxygen in Gd-O solid solution to the surface also plays an important role in removal of oxygen. The substances are confirmed by optical emission spectroscopy (OES), which are involved in the plasma like Ar I, Ar II and H I and some possible reactions. The effect of $\mathrm{H}$ with thermodynamic estimation was discussed in detail.
\end{abstract}

Key words: Gd; hydrogen; oxygen; HPAM

In recent years, rare earth $(\mathrm{Gd})$ materials and compounds are characterized by a variety of particular physical and chemical properties, which means possibilities for wide applications as functional materials, therefore, the rare-earth metals $(\mathrm{Gd})$ and compounds have been known to be widely used in permanent magnets ${ }^{[1]}$ and corrosion resistance materials ${ }^{[2]}$. At the same time, rare earth element addition in $\mathrm{Cu}(\mathrm{Mg})$-based alloys is applied extensively to refine grain size and to improve the mechanical properties ${ }^{[3,4]}$. However, almost all rare earth metals show sensitivity to oxygen, including the dissolution of very small amounts of oxygen ${ }^{[5]}$. Oxygen, in particular, has no benefit to the physical properties of them. But, there are many technological difficulties and complex problems due to high chemical reactivity of RE. Now, the preparation and characterization of plasma arc melting (PAM) have been widely reported as a practical and useful melting method for various refractory metals. Sometimes, it can be used to eliminate non-metallic impurities from some metals. It has been found, however, that an addition of $\mathrm{H}_{2}$ significantly improves the removal of some nonmetallic elements from refractory metals such as $\mathrm{Mo}$ and $\mathrm{Cr}^{[6,7]}$. Many important factors of the hydrogen plasma arc melting, such as thermal, chemical and physical explaining have not been reported so far. The research related with these processes is of great importance, both for the development of manufacturing rare earth technology and for extending the applications of these metals. For these considerations, we reported how to deal with the relation between rare earth and oxygen in the present work, laying the foundation for characterizing the preparing process of "oxygen-free" Gd thermally and chemically. Optical emission spectroscopy (OES) was used for plasma processes, which can identify the species in the plasma by analyzing optical radiation of excited plasma species ${ }^{[8]}$. This technique enabled us to know the status of Ar and H, But it has been seldom used for analyzing the details of the HPAM process now. So, we evaluated the effect of $\mathrm{H}$ by the emission spectra which contained a whole quantity of information.

\section{Experiment}

Commercial Gd (above $99.5 \mathrm{wt} \%$ in purity by the supplier) was used as starting material and the purity of $\mathrm{Gd}$ was raised up to $99.96 \%$ after $\mathrm{Ar}-\mathrm{H}_{2}$ PAM. Samples were refined by plasma arc melting, and the detailed constitution of the furnace has been described in elsewhere ${ }^{[9]}$. The plasma

Received date: October 14, 2015

Foundation item: Project of the Ministry of Science and Technology of China (2012CBA01207, 2010CB631301); National Natural Science Foundation of China (U1201241, 11375020, 21321001)

Corresponding author: Li Xingguo, Professor, College of Chemistry and Molecular Engineering, Peking University, Beijing 100871, P. R. China, Tel: 0086-10-6765930, E-mail: xgli@pku.edu.cn

Copyright (C) 2016, Northwest Institute for Nonferrous Metal Research. Published by Elsevier BV. All rights reserved. 
torch is a dc arc discharged type with a maximum power of $35 \mathrm{~kW}$. Gd $(10 \mathrm{~g})$ and $\mathrm{Y}(10 \mathrm{~g})$ were placed on the water-cooled copper crucible by $\mathrm{Ar}-\mathrm{H}_{2}(20 \mathrm{vol} \%)$ plasma arc under atmospheric pressure. The samples were turned upside down and melted for uniform refining. The melting time was total time. The flow rate of the plasma generating gas introduced to the chamber was constantly $5 \mathrm{~L} / \mathrm{min}$. "Oxygen-free" Gd are still big challenges. An O-N analyzer was used to determine the oxygen concentrations in $\mathrm{Gd}$ before and after melting.

Oxygen concentrations were estimated by repeating measurements several times for each isotope. An OES (AvaSpec-2048FT-SPU, measured from $181 \mathrm{~nm}$ to $1100 \mathrm{~nm}$ in $0.8 \mathrm{~nm}$ steps) was used to obtain emission spectra of the $\mathrm{Ar}-\mathrm{H}_{2}$ PAM. The laboratory-scale plasma arc furnace is schematically shown in Fig.1.

\section{Results and Discussion}

Gd was melted after melting $\mathrm{Y}$ upside down as an external getter. It has been reported that rare earth metals $(\mathrm{RE}=\mathrm{Gd}, \mathrm{Tb}, \mathrm{Dy}, \mathrm{Er})$ containing $1 \mathrm{wt} \%$ oxygen can be deoxidized either by calcium or yttrium metal ${ }^{[10]}$. So Y can react with $\mathrm{O}$ in the chamber which will promote diffusion of $\mathrm{O}$ in $\mathrm{Gd}$ to the surface. For the description of experimental data, the removal efficiency of $\mathrm{O}$ is defined by Eq. (1):

Removal efficiency $=100 \%\left(C_{\mathrm{i}}-C_{\mathrm{f}}\right) / C_{\mathrm{i}}$

where, $C_{\mathrm{i}}$ and $C_{\mathrm{f}}$ are the initial and final concentrations of $\mathrm{O}$, respectively.

Fig.2a shows the dependence of removal efficiency of oxygen under the different $\mathrm{H}_{2}$ contents in the plasma gas. Rapid increasing of removal efficiency occurs by Ar- $\mathrm{H}_{2}$-PAM compared with by Ar PAM. It is found that Ar- $20 \mathrm{H}_{2}$ PAM provides excellent deoxidation. It has also been reported that refining effect gradually decreased with increasing the hydrogen content over $20 \%$, because of the unstable plasma arc at higher hydrogen content ${ }^{[7]}$. Fig. $2 b \sim 2 d$ show the relations between oxygen concentrations and removal efficiency with the melting time. Concentration of oxygen is decreased with the melting time; however the

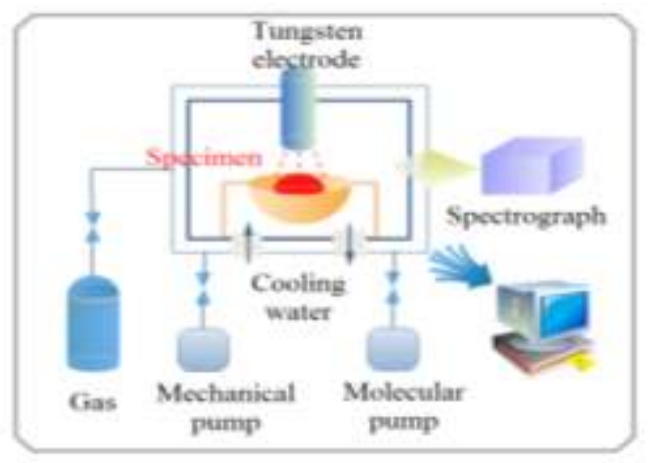

Fig.1 Experimental setup removal efficiency is increased at the same time. Then, concentration of oxygen is reduced more rapidly by $\mathrm{Ar}-\mathrm{H}_{2}$ PAM compared with by Ar PAM even when external getter $\mathrm{Y}$ is used. Removal efficiency is up to $94.7 \%$ by $\mathrm{Ar}-\mathrm{H}_{2} \mathrm{PAM}$ compared with Ar-PAM (41.1\%) and Ar-PAM + Y (65.6\%) melted for $30 \mathrm{~min}$.

Fig.3 shows the removal efficiency of oxygen at different currents with optical spectra taken at 65 and $120 \mathrm{~A}$. The spectra show some species like Ar I, ArII and H I. Some possible reactions are observed and they are presented as follows:
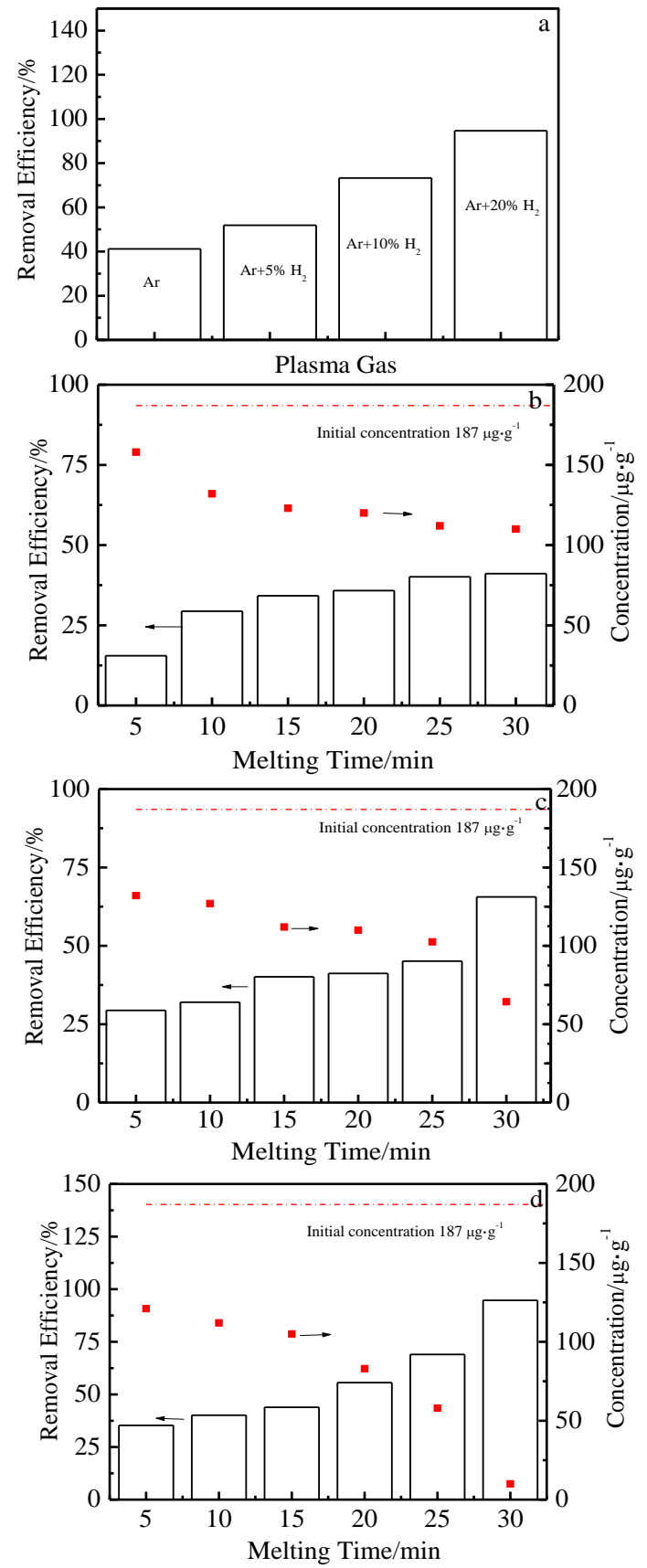

Fig.2 Relation between removal efficiency and content of $\mathrm{H}_{2}$ during melting (a); removal efficiency and concentration change of oxygen as a function of melting time refined by $\operatorname{Ar}-\mathrm{PAM}(\mathrm{b}), \mathrm{Ar}-\mathrm{PAM}+\mathrm{Y}(\mathrm{c})$, and $\mathrm{Ar}-20 \% \mathrm{H}_{2} \mathrm{PAM}+\mathrm{Y}(\mathrm{d})$ 


$$
\begin{aligned}
& \mathrm{H}_{2}+\mathrm{e} \rightarrow 2 \mathrm{H} \mathrm{I}+\mathrm{e} \\
& \mathrm{H} \mathrm{I}+\mathrm{e} \rightarrow \mathrm{H} \mathrm{I}^{*}+\mathrm{e} \\
& \mathrm{HI}+\mathrm{e} \rightarrow \mathrm{H} \mathrm{II}+2 \mathrm{e}
\end{aligned}
$$

The asterisk in $\mathrm{H} \mathrm{I}^{*}$ means an excitation state. Collisions of molecule-molecule and ion-molecules are numerous in the arc. During the melting, the ions are accelerated by the electric field and get energy from electrons through elastic and inelastic collisions. In the spectrum, $I_{\mathrm{H}} / I_{\mathrm{Ar}}$ in $120 \mathrm{~A}$ is two times higher than that in $65 \mathrm{~A}$. This means all these are connected with the temperature and the main driving force chemically are induced by activated hydrogen atoms during HPAM. The oxygen removal efficiency could be enhanced by activated hydrogen atoms as indicated in Fig.3.

The Gibbs free energies of different reactions of molten Gd can be determined from the reactions in Fig.4. The thermodynamic data for solid Gd were used for calculation at higher temperatures because the thermodynamic data of oxygen in molted Gd has never been reported yet. These equations indicate the deoxidation reactions by $\mathrm{H}_{2}$ and $\mathrm{H}$, respectively, and the respective $\Delta G$ with temperature.

Fig.4 shows the relationship between $\Delta G$ of these reactions with temperature. The reaction of $\mathrm{Gd}$ with $\mathrm{H}_{2}$ is more difficult because of the values of $\Delta G$ close to zero or positive. Then, deoxidation by $\mathrm{H}$ is evaluated to be favorable due to the lower $\Delta G$. So, atomic $H$ has higher deoxidizing power compared with molecular $\mathrm{H}_{2}$ and the thermodynamical calculation agrees well with the results of experimental deoxidation.

On the other hand, an increase in the temperature of the melt can be caused by the high thermal conductivity of the hydrogen plasma, including the heat of recombination of $\mathrm{H}$, supersaturated in the melt and to $\mathrm{H}_{2}$ at the molten metal surface. Diffusion of oxygen in Gd-O solid solution to the surface is believed to be the rate determining step in the processes. At $1508 \mathrm{~K}$, the crystal structure of $\mathrm{Gd}$ is transformed from hcp to bcc and the diffusion coefficient

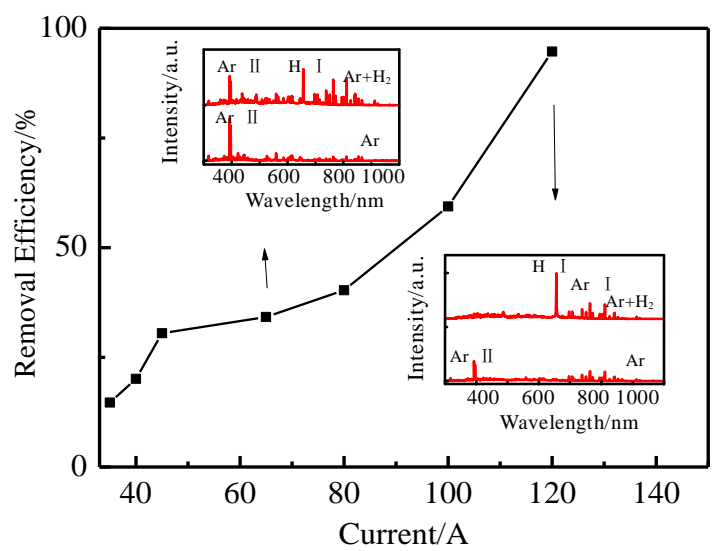

Fig.3 Removal efficiency of oxygen at different currents with OES spectra collected from the samples treated in 65 and $120 \mathrm{~A}$ of oxygen is increased approximately from $10^{-10}$ to $10^{-8}$ $\mathrm{m}^{2} \cdot \mathrm{s}^{-1}$. The diffusion rate of oxygen to the surface are increased. These will help to increases removal of oxygen.

The effect of activated hydrogen atoms should be concluded as follows: it is of both thermal and chemical significance during the rapid diffusions of oxygen to the melt surface. At the same time, surface-active agents and thin oxide film on the melt surface are removed by the active hydrogen atoms due to increasing temperature of the $\mathrm{Gd}$. It can be evaluated that vaporization of some metal and nonmetal elements can be accelerated more easily when the surface of Gd is not included with the active agents and thin solid film. And then, the diffusion rate of metal elements from the Gd surface to the gaseous layer can be also raised remarkably during HPAM. All these facts suggest an important driving force, which lead to transfer of volatile elements into the gas phase, is enhanced by the activated hydrogen atoms through a dynamic interaction. The purifying mechanism can be clarified as follows: the counter- diffusion of active hydrogen atoms trap the volatile atoms in the gaseous boundary layer and take them into the gas phase. This process can be indicated as the follow equation.

$$
x \mathrm{M}(\text { vap })+y \mathrm{H} \rightarrow\left(\mathrm{M}_{x}-\mathrm{H}_{y}\right) \rightarrow x \mathrm{M}(\mathrm{g})+y / 2 \mathrm{H}_{2}
$$

This tendency for nonmetal elements is analogous to the result. In metal, oxygen is combined with metal elements to form new phases. During HPAM, metal elements are evaporated and oxygen or other nonmetal elements are diffused to the surface and then would be removed. At the same time, active hydrogen atoms are dissociated to the melting surface from the arc. Most of the active hydrogen atoms can reach the $\mathrm{Gd}$ surface and contribute to the reactions with oxygen, although some of them may be recombined near the molten surface because of decreasing temperature. The relation between oxygen and Gd during HPAM can be discussed thermodynamically as follows. First, the diffusion rates of oxygen to the surface is

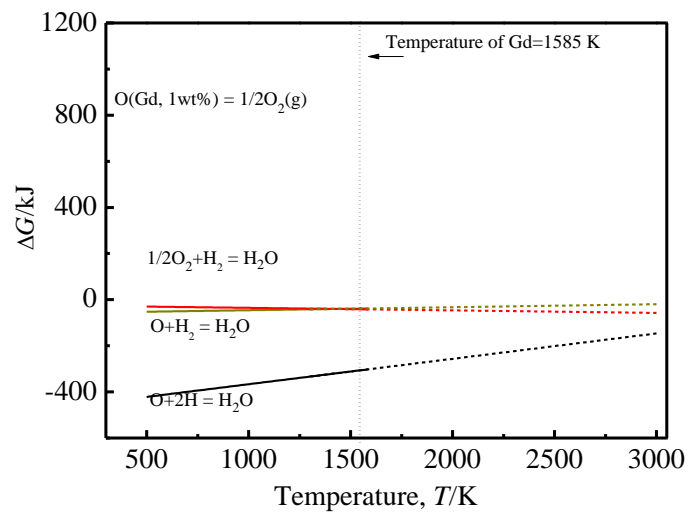

Fig.4 Free energy changes with temperature for deoxidation of Gd by $\mathrm{H}$ and $\mathrm{H}_{2}$ 
increased because of high temperature; second, activated hydrogen atoms contribute to the removal reactions not only thermally but also chemically; the last but very important one, the vaporization of the volatile elements can be progressed and all these discussions are suited to other nonmetal elements.

\section{Conclusions}

1) An excellent effect for fabricating the "oxygen-free" $\mathrm{Gd}$ is found in the hydrogen plasma arc melting. Removal efficiency is up to $94.7 \%$ by $\mathrm{Ar}-\mathrm{H}_{2}$ PAM. A remarkable decrease in oxygen of $\mathrm{Gd}$ is observed compared with $\mathrm{Ar}$ plasma-arc melting. All these are obviously ascribed to the activated hydrogen atoms dissociated in a high temperature plasma-arc and the interaction between $\mathrm{H}$ and $\mathrm{O}$ (in $\mathrm{Gd}$ ) which is enhanced because of the increasing temperature at the surface of the molten metal.

2) This approach can be potentially used to prepare other "oxygen-free" rare earth metals which are highly active in air. It enables comprehensive studies on the effect of $\mathrm{H}$ in detail.

\section{References}

1 Uda T, Jacob K T, Hirasawa M. Science[J], 2000, 289: 2326

2 Amadeh A, Pahlevani B, Heshmati-Manesh S. Corrosion Science $[\mathrm{J}], 2002,44: 2321$

3 Xu J. Journal of Alloys and Compounds[J], 2008, 448: 2331

4 Gao L, Chen R, Han E. Journal of Alloys and Compounds [J], 2009, 481: 379

5 Song X Y, Zhang J X, Yue M et al. Advanced Materials[J], 2006, 18: 1210

6 Mimura K, Komukai T, Isshiki M. Materials Science and Engineering $A[\mathrm{~J}], 2005$, 403: 11

7 Lim J W, Mimura K, Miyawaki D et al. Materials Letters[J], 2010, 64: 2290

8 Andujar J L, Pascual E, Viera G et al. Thin Solid Films[J], 1998, 317: 120

9 Mimura K, Lim J W, Oh J M et al. Materials Letters[J], 2010, 64: 411

10 Okabe T H, Hirota k, Kasai E et al. Journal of Alloys and Compounds[J], 1998, 279: 184

\title{
无氧钆金属新型制备方法
}

\author{
李 里 ${ }^{1}$, 李国玲 ${ }^{1,4}$, 徐 丽 $^{2}$, 熊义富 ${ }^{3}$, 李星国 ${ }^{1}$ \\ (1. 北京大学, 北京 100871)
}

(2. 国家电网全球能源互联网研究院 未来科技城北区国网智能电网研究院, 北京 102211)

(3. 四川材料与工艺研究所, 四川 绵阳 621907)

(4. 青岛大学, 山东 青岛 266071)

摘 要: 采用氢等离子体电弧熔炼技术制备了无氧稀土金属钝。相比传统的氩气等离子体电弧熔炼技术, 该方法除氧效果更明显。这 得益于熔炼过程中高温下分解和激化的氢原子。熔炼过程中氧由基体金属内部迁移至表面也发挥了重要作用。采用光谱测试仪检测到 了 $\mathrm{Ar}$ I、Ar II、H I 及其他多个可能的反应。在文章中详细探讨了氢原子热力学反应。

关键词: 钝; 氢; 氧; 氢等离子体电弧熔炼

作者简介: 李 里, 女, 1977 年生, 博士生, 北京大学化学与分子工程学院, 北京 100871, 电话: 010-62753691, E-mail: liliwhitesnow@163.com 